\title{
The homogeneity of low cyanide contents in Jiaozhou Bay
} Dongfang Yang ${ }^{1,2,4, a}$, Sixi Zhu ${ }^{1,2}$, Danfeng Yang ${ }^{3}$, Yunjie $\mathrm{Wu}^{1,2}$ and Fengyou

${ }^{1}$ Research Center for Karst Wetland Ecology, Guizhou Minzu University, Guizhou Guiyang, Guizhou Guiyang, China

\author{
${ }^{2}$ College of Chemistry and Environmental Science, Guizhou Minzu University, Shanghai, 550025, \\ China \\ ${ }^{3}$ College of Information Science and Engineering, Fudan University, Shanghai, 200433, China \\ ${ }^{3}$ North China Sea Environmental Monitoring Center, SOA, Qingdao 266033, China \\ adfyang_dfyang@126.com; ${ }^{b}$ Corresponding author; wangfy2001@yahoo.com.cn.
}

\begin{abstract}
Keywords: Cyanide; Distribution; Low content; Homogeneity; Jiaozhou Bay.
\end{abstract}
\begin{abstract}
Based on the investigation data on cyanide in bottom waters in the bay mouth of Jiaozhou Bay in 1983, we analyzed the contents, pollution levels, and distributions of cyanide. Results showed that cyanide contents in bottom waters in 1983 were $0.02-0.34 \mu \mathrm{g} \mathrm{L} \mathrm{L}^{-1}$, and were much lower than guide line of cyanide in Grade I $\left(5.00 \mu \mathrm{g} \mathrm{L}^{-1}\right)$ of National Sea Water Quality Standard (GB 3097-1997), indicated that the pollution levels of cyanide in this bay in 1983 were very low. There were high value regions in the inside of the bay mouth, yet were low value regions in the out side of the bay mouth, indicated that there were aggregation and divergence processes of cyanide in the bay. Cyanide contents were decreasing from the inside of the bay mouth (0.06-0.34 $\left.\mu \mathrm{g} \mathrm{L}^{-1}\right)$ to the bay mouth and then the outside of the bay mouth $\left(0.02-0.04 \mu \mathrm{g} \mathrm{L}^{-1}\right)$. The substances could be transported to everywhere even the input of cyanide was low content, and the contents of cyanide would be homogeneity in waters. These findings are strongly proving the homogeneity of the ocean.
\end{abstract}

\section{Introduction}

Cyanides such as editpotassium cyanide and sodium cyanide have been widely used in industry and agriculture, and the cyanide-containing waste water has been serious environmental issues in many countries and regions due to the high toxicity of cyanide. The pollution in the marine bay could be harmful to human being by means of food chain, and the research on the contents and transfer process of cyanide is essential to environmental protection [1-2]. This paper analyzed the content, distribution and homogeneity of cyanide in the bottom waters in the bay mouth of Jiaozhou Bay, China, and revealed the exist and migration of cyanide in this bay.

\section{Material and method}

Jiaozhou Bay $\left(35^{\circ} 55^{\prime}-36^{\circ} 18^{\prime} \mathrm{N}, 120^{\circ} 04^{\prime}-120^{\circ} 23^{\prime} \mathrm{E}\right)$ is located in the south of Shandong Peninsula, eastern China (Fig. 1). The total area, average water depth and bay mouth width are 446 $\mathrm{km}^{2}, 7 \mathrm{~m}$ and $3 \mathrm{~km}$, respectively. This semi-closed bay has more than ten inflow rivers such as Haibo Rriver, Licun Rriver, Baisha Rriver, and Loushan Rriver etc., most of which have seasonal features[3-4], and have been input channels of various pollutants to the bay [1-2].

The data was provided by North China Sea Environmental Monitoring Center. The survey was conducted in May, September and October 1983 (Fig. 1). Cyanide in surface waters was collected and measured followed by National Specification for Marine Monitoring [5]. 


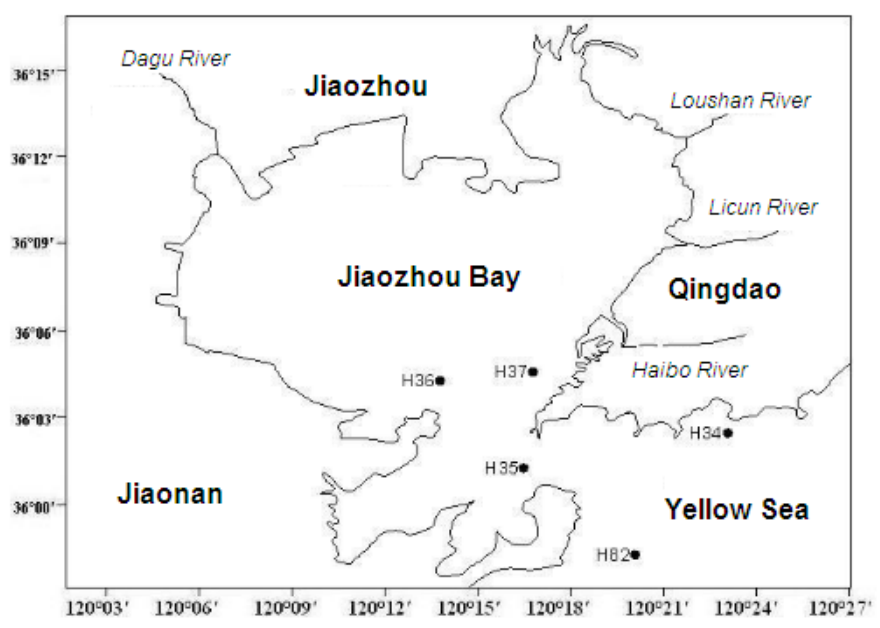

Fig.1 Geographic location and monitoring sites in Jiaozhou Bay

\section{Results and discussion}

Content and pollution level of cyanide. The contents of cyanide in bottom waters in May, September and October were 0.04-0.06 $\mu \mathrm{g} \mathrm{L}^{-1}, 0.02-0.25 \mu \mathrm{g} \mathrm{L}^{-1}$ and $0.03-0.34 \mu \mathrm{g} \mathrm{L}^{-1}$, respectively (Fig. 1). Once cyanide was transported to the bay, it was firstly arrived to the surface waters, and would be transferred to the bottom waters by means of vertical water's effect [6]. Hence, the contents of cyanide in bottom in Jiaozhou Bay were ranging from $0.02 \mu \mathrm{g} \mathrm{L}^{-1}$ to $0.34 \mu \mathrm{g} \mathrm{\textrm {L } ^ { - 1 }}$ during the whole year. In according to the guide line of cyanide in Grade I $\left(5.00 \mu \mathrm{g} \mathrm{L}^{-1}\right)$ of National Sea Water Quality Standard (GB 3097-1997), the contents of cyanide in 1983 in bottom waters in Jiaozhou Bay were still very low, and this bay was very slightly polluted by cyanide in the early stage of Reform and Opening.

Distributions and homogeneity of cyanide. In May, there was a high value region around Site $\mathrm{H} 37$ in the coastal area in the east of the bay, and there were a series of different gradient paralle lines which were decreasing from the high value center $\left(0.06 \mu \mathrm{g} \mathrm{L}^{-1}\right)$ to the bay mouth in the south and then the outside of the bay mouth $\left(0.04 \mu \mathrm{g} \mathrm{L}^{-1}\right)$ (Fig. 2). In September, there was also a high value region around Site H37 in the coastal area in the east of the bay, and there were a series of different gradient parallel lines which were decreasing from the high value center $\left(0.25 \mu \mathrm{g} \mathrm{L}^{-1}\right)$ to the bay mouth in the south and then the outside of the bay mouth $\left(0.02 \mu \mathrm{g} \mathrm{L}^{-1}\right)$ (Fig. 3). In October, there was also a high value region around Site H37 in the coastal area in the east of the bay, and there were a series of different gradient parallel lines which were decreasing from the high value center $\left(0.34 \mu \mathrm{g} \mathrm{L}^{-1}\right)$ to the bay mouth in the south and then the outside of the bay mouth $\left(0.03 \mu \mathrm{g} \mathrm{L}^{-1}\right)$ (Fig. 4).

The contents of the substances were decreasing along with the water exchange in the bay [7]. Cyanide contents were decreasing from the inside of the bay mouth to the bay mouth and then the outside of the bay mouth in different seasons, indicating the high sedimentation rate inside the bay mouth and low sedimentation rate outside the bay mouth. The current flow rate in the side of the bay mouth was relative high, yet in the outside of the bay mouth was relative low, and the transportation of cyanide was mainly determined by the flow rate. There were high value region or low value regions in the inside of the bay mouth or the outside of the bay mouth, indicated the aggregation and divergence processes by means of water movement. 


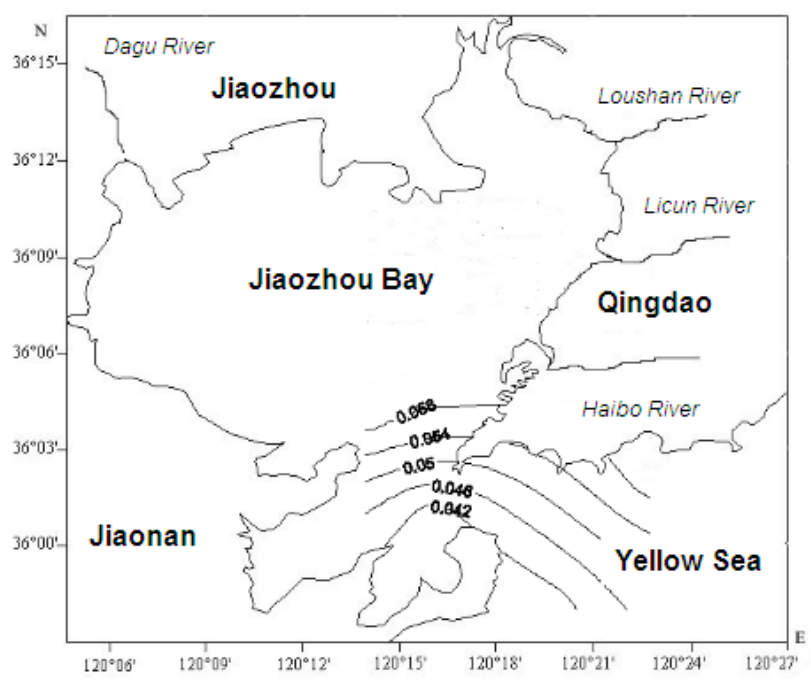

Fig. 2 Spatial distribution of cyanide in bottom waters in Jiaozhou Bay in May 1983/ $\mu \mathrm{g} \mathrm{L}^{-1}$

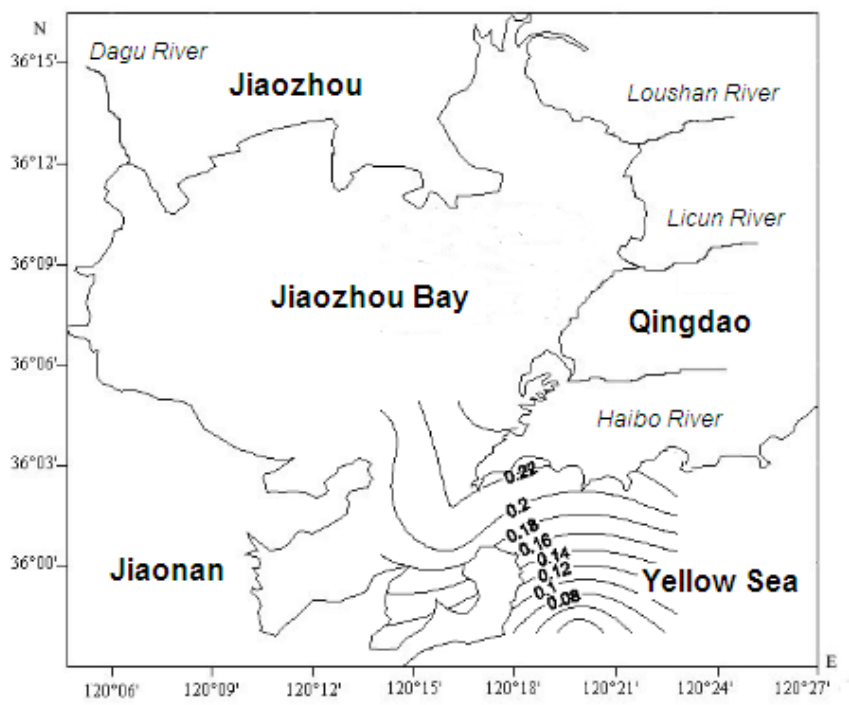

Fig. 3 Spatial distribution of cyanide in bottom waters in Jiaozhou Bay in May 1983/ $\mu \mathrm{g} \mathrm{L}^{-1}$

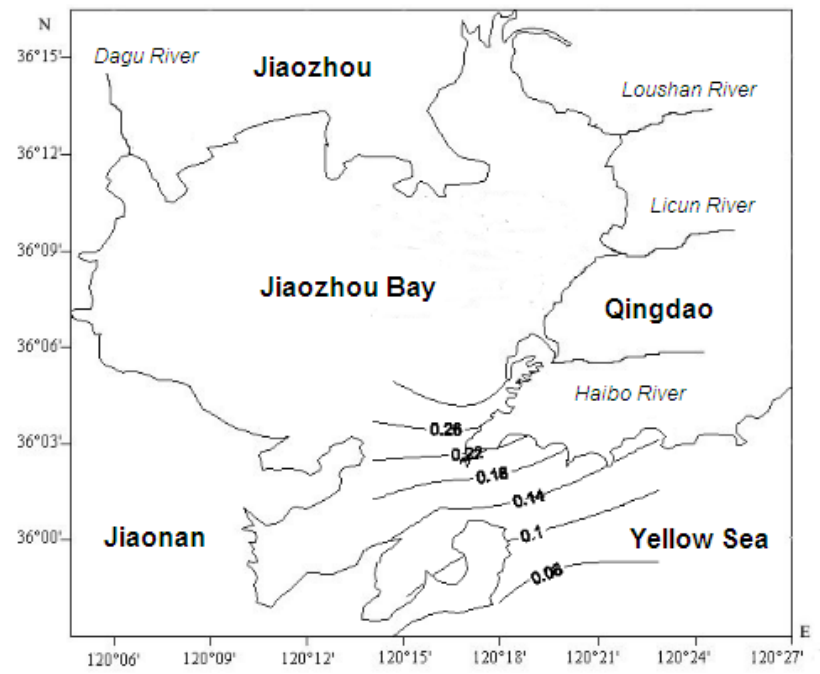

Fig. 4 Spatial distribution of cyanide in bottom waters in Jiaozhou Bay in May 1983/ $\mu \mathrm{g} \mathrm{L}^{-1}$

The homogeneity process of cyanide. The substances in the ocean were continually stirred and transported by tide and current, leading to the homogeneity of the substances. The tide was playing the dominant role in coastal waters, while in the deep sea the main role was marine current, as well 
as storm tide and submarine earthquake. Hence, the contents of the substances would be homogeneous distribution as time pass by, and the ocean has the feature of homogeneity [8]. River flow and marine terminal were the major sources of cyanide in Jiaozhou Bay, whose input strengths were $0.14-0.46 \mu \mathrm{g} \mathrm{L}^{-1}$. By means of the vertical water's effect [6], there were high value regions around Site H37 in the coastal area in the east of the bay $\left(0.06-0.34 \mu \mathrm{g} \mathrm{L}^{-1}\right)$. There was a deep water channel in the bay mouth $(40 \mathrm{~m})$, and the contents of the substances were continually decreasing along with the water exchange [7]. Hence, the relative low contents of cyanide in the bottom waters inside the bay mouth was transported to the outside of the bay mouth, and therefore the contents of cyanide were decreasing from the inside of the bay mouth to the bay mouth and then the outside of the bay mouth. These finding were proving the homogeneity of the ocean. By means of the homogenity of the ocean, the substances could be transported the anywhere as long as the coverage area of the marine current, even the contents of cyanide were very low $\left(0.06-0.34 \mu \mathrm{g} \mathrm{L}^{-1}\right)$, and of course the contents would be decreasing to lower values $\left(0.02-0.04 \mu \mathrm{g} \mathrm{L}^{-1}\right)$.

\section{Conclusion}

The content of cyanide in bottom waters was very low and this bay was very slightly polluted by cyanide in 1983. Cyanide contents were decreasing from the inside of the bay mouth to the bay mouth and then the outside of the bay mouth in different seasons. There were aggregation process and divergence process by means of water movement. By means of the homogeneity of the ocean, the substances could be transported the anywhere as long as the coverage area of the marine current, even the contents of cyanide were very low.

\section{Acknowledgment}

This research was sponsored by Doctoral Degree Construction Library of Guizhou Nationalities University, Education Ministry's New Century Excellent Talents Supporting Plan (NCET-12-0659), the China National Natural Science Foundation (31560107), Major Project of Science and Technology of Guizhou Provincial ([2004]6007-01), Guizhou R\&D Program for Social Development (Qiankehe SZ zi [2014] 3036) and Research Projects of Guizhou Nationalities University ([2014]02), Research Projects of Guizhou Province Ministry of Education (KY [2014] 266), Research Projects of Guizhou Province Ministry of Science and Technology (LH [2014] 7376).

\section{References}

[1] Yang DF, He XH, Gao J, et al.: Materials, Environmental and Biological Engineering. Vol. (2015), p. 40-43.

[2] Yang DF, He XG, Gao J, et al.: Advanced Materials Research, Vol.1092-1093 (2015), p. 992-995.

[3] Yang DF, Chen Y, Gao ZH, et al.:Chinese Journal of Oceanology Limnology, Vol. 23(2005), p. 72-90.

[4] Yang DF, Wang F, Gao ZH, et al.: Maine Science, Vol. 28(2004): 71-74. (in Chinese with English abstract)

[5] State Ocean Administration. The specification for marine monitoring: Beijing, Ocean Precess, (1991).

[6] Yang DF, Wang FY, He HZ, et al.: Proceedings of the 2015 international symposium on computers and informatics, 2015, p. 2655-2660.

[7] Yang DF, Miao ZQ, Xu HZ, et al.: Marine Environmental Science, Vol. 332 (2013), p. 373-380. (in Chinese)

[8] Yang DF, Ding ZR, Zheng L, et al.: Coastal Enginerring, Vol. 32 (2011), p. 66-74. 